\title{
Self-Compassion Mahasiswa Tingkat Akhir Prodi Bimbingan dan Konseling pada Masa Pandemi Covid-19
}

\author{
Ismarini Bekti Setiani \\ Program Studi Bimbingan dan Konseling, Fakultas Ilmu Pendidikan, \\ Universitas Negeri Yogyakarta \\ ismarinibektis@uny.ac.id
}

\begin{abstract}
Abstrak
Kesulitan yang dirasakan mahasiswa tingkat akhir di masa pandemi covid-19 yang membatasi ruang gerak dalam proses penyeleasian tugas akhir mahasiswa. Tekanan mental mahasiswa menghadapi kesulitan-kesulitan yang terjadi dapat berdampak pada stress, depresi yang akhirnya lebih memilih menyerah dan tidak menyelesaikan tugas akhir, bahkan sampai memunculkan ide untuk bunuh diri. Beban dan kesulitan yang dirasakan mahasisawa tingkat akhir pada masa pandemi ini agar tidak menjadi tekanan yang berlarut dan berdampak pada kesehatan (fisik maupun mental) serta kelancaran penyelesaian kuliah maka mahasiswa tingkat akhir perlu memiliki self-compassion (welas diri). Dengan memiliki self-compassion yang tinggi pada mahasiswa maka menimbulkan resiliensinya tinggi dan prokrastinasi rendah, serta lebih termotivasi untuk berjuang lebih baik dalam proses penyelesaian tugas akhir khususnya di era pandemi covid-19. Tujuan penelitian ini adalah mengetahui gambaran tingkat selfcompassion (welas diri) mahasiswa tingkat akhir prodi bimbingan dan konseling Universitas Negeri Yogyakarta pada masa pendemi covid-19. Penelitian ini menggunakan pendekatan kuantitatif, dengan jenis penelitian deskriptif dan menggunakan analisis deskriptif. Sampel dalam penelitian ini adalah mahasiswa tingkat akhir prodi bimbingan dan konseling di Universitas Negeri Yogyakarta yang memiliki kriteria tertentu yaitu mahasiswa yang telah menyelesaikan KKN dan praktik kependidikan serta sedang menyusun tugas akhir sebanyak 36 mahasiswa. Hasil penelitian menunjukkan mahasiswa sebagian besar memiliki self-compassion kategori sedang. Komponen self-compassion yang masih perlu ditingkatkan yaitu kewawasan (mindfulness) dan komponen yang perlu dikurangi yaitu menghakimi diri, isolasi, dan overidentifikasi. Diperlukan adanya intervensi untuk membantu mahasiswa tingkat akhir dalam meningkatkan self-compassion.
\end{abstract}

Kata Kunci: Self-Compassion; Mahasiswa Tingkat Akhir; Pandemi Covid-19.

\section{PENDAHULUAN}

Pandemi covid-19 yang masih terjadi sampai saat ini membawa dampak untuk masyarakat, tidak hanya dalam bidang kesehatan tetapi juga dalam segala bidang kehidupan 
masyarakat. Pada bidang pendidikan, dampak yang terjadi salah satunya di pendidikan tinggi bagi para mahasiswa. Jika pada mahasiswa khususnya tingkat awal, dampak yang dirasakan adalah pada saat proses perkuliahan berlangsung yaitu tidak lagi dengan tatap muka langsung tetapi dilakukan secara online atau daring.

Berdasarkan pengalaman perkuliahan yang telah berlangsung, secara umum mahasiswa mengeluhkan beberapa hal yang membuatnya lebih memilih perkuliahan dilakukan secara tatap muka langsung. Mahasiswa mengeluhkan interaksi mahasiswa dengan dosen terbatas sehingga tidak dapat berinteraksi langsung secara lancar dan leluasa dengan dosen. Hal ini membuat pemahaman materi kurang mampu dipahami dan perkuliahan kurang efektif jika dibandingkan dengan perkuliahan secara tatap muka langsung. Selain itu, kendala seperti jaringan dan peralatan teknis lain terkait perkuliahan daring serta banyaknya tugas yang dibebankan jauh lebih banyak ketika daring.

Namun, di sisi lain perkuliahan pada saat pandemi juga memberi dampak positif salah satunya dalam meningkatkan kemandirian belajar. Himbauan agar mahasiswa belajar dari rumah selama Pandemi Covid-19 secara megejutkan mampu meningkatkan kemandirian belajar mahasiswa (Firman, 2020). Lingkungan pembelajaran online memberikan kebebasan kepada mahasiswa untuk merencanakan dan melaksanakan pembelajarannya (Firman, 2020). Bagi mahasiswa tingkat akhir dampak yang dialami selain perkuliahan daring, mahsiswa juga merasakan hambatan dalam pelaksanaan kuliah kerja nyata dan praktik lapangan atau praktik kependidikan serta yang paling dirasakan adalah dalam proses penyelesaian tugas akhir skripsi.

Kuliah Kerja Nyata dan Praktik Kependidikan dilakukan secara daring dan pengerjaan skripsi terutama dalam hal pengumpulan data juga terkendala akibat pandemi, hal ini menjadi beban sendiri untuk mahasiswa tingkat akhir. Beberapa tuntutan dan beban tugas mahasiswa tingkat akhir di masa pandemi ini memberi dampak bagi sisi psikologis mahasiswa tingkat akhir. Tekanan dan beban yang dirasakan dapat mengganggu kesehatan mental mahasiswa jika dibiarkan berlarut. Beban dan kesulitan yang dirasakan mahasisawa tingkat akhir pada masa pandemi ini agar tidak menjadi tekanan yang berlarut dan berdampak pada kesehatan (fisik maupun mental), serta kelancaran penyelesaian perkuliahan maka mahasiswa tingkat akhir perlu memiliki self-compassion (welas diri). Selfcompassion has been consistently linked with positive mental health (Bluth \& Neff, 2018).

Self-compassion entails treating oneself with kindness, recognizing one's shared humanity, and being mindful when considering negative aspects of oneself (Neff \& Vonk, 2009). Individu yang memiliki self-compassion adalah individu yang memiliki kebaikan dan kepedulian pada diri sendiri ketika menghadapi rintangan, kesulitan hidup, ataupun hal negatif pada diri sendiri. Self-compassion sama halnya dengan menyayangi diri sendiri. Menyayangi diri sendiri berarti menjaga diri sendiri seperti yang akan dilakukan untuk orang yang dicintai (Germer dalam Elices, dkk, 2017). Karinda (2020) menyatakan bahwa belas kasih diri cenderung memiliki kasih sayang yang melibatkan diri sendiri seperti bersikap baik kepada diri sendiri dan bukannya mengkritik pada diri sendiri, tetapi lebih melihat 
penderitaan, kegagalan dan kekurangan sebagai bagian dari kehidupan manusia pada umumnya. Secara keseluruhan, itu mencakup pengakuan bahwa kelemahan dan kekecewaan adalah bagian dari pengalaman manusia dan setiap manusia akan mengalaminya, maka dari itu diri kita sendiri juga pantas menerima belas kasihan (Karinda, 2020).

Berdasarkan pernyataan mahasiswa tingkat akhir di Universitas Negeri Yogyakarta khususnya yang telah menyelesaikan KKN dan praktik kependidikan, kesulitan dalam menghadapi penyelesaian tugas akhir skripsi dimana kendala dalam bimbingan dan proses pengumpulan data merupakan hal sulit yang dirasakan mahasiswa tingkat akhir di masa pandemi ini. Beban tugas yang dipikul oleh mahasiswa tingkat akhir menimbulkan tekanan mental jika tidak ada self-compassion pada diri mahasiswa. Pada dasarnya penyelesaian tugas akhir mahasiswa memiliki tingkat kesulitan tersendiri bagi mahasiswa walaupun saat sebelum keadaan pandemi berlangsung.

Menurut Maritapiska (dalam Aulia dan Panjaitan, 2019) kesulitan yang dirasakan diantaranya proses revisi yang berulang-ulang, kesulitan mendapatkan referensi, lamanya umpan balik dari dosen pembimbing ketika menyelesaikan skripsi, keterbatasan waktu penelitian, dosen pembimbing yang sibuk dan sulit ditemui. Kesulitan yang dirasakan bertambah ketika pandemi covid-19 beralngsung yang membatasi ruang gerak dalam proses penyeleasian tugas akhir mahasiswa. Tekanan mental dalam menghadapi kesulitan-kesulitan yang terjadi dapat berdampak pada stress, depresi yang akhirnya lebih memilih menyerah dan tidak menyelesaikan tugas akhir, bahkan sampai memunculkan ide untuk bunuh diri.

American College Health Association-National College Health Assesment (ACHANCHA) pada tahun 2011 meneliti perjalanan mahasiswa dari tahun ke dua hingga empat diberbagai institusi pendidikan di Amerika, dan menemukan ada 30\% dari mahasiswa yang menyatakan bahwa "merasa tertekan hingga tidak dapat berbuat apa-apa" terutama pada tingkat akhir (Krisdianto \& Mulyanti, 2015). Kasus mahasiswa suatu perguruan tinggi di Sumatra Utara berinisial FAP 23 tahun, bunuh diri akibat deadline skripsi (Krisdianto \& Mulyanti, 2015). Khalika dalam Aulia dan Panjaitan (2019) menuliskan berita pada media berita online tirto.id mengenai kasus dua mahasiswa perguruan tinggi di Jawa Barat berinsial MB dan RWB berusia 23 tahun bunuh diri pada desember 2018 akibat depresi kala mengerjakan skripsi.

Beberapa fenomena yang terjadi yaitu kasus bunuh diri pada mahasiswa tingkat akhir dan ada juga yang menyerah dengan tidak menyelesaikan tugas akhir merupakan hal yang tidak diinginkan terjadi. Mahasiswa tingkat akhir memerlukan adanya self-compassion (belas kasih diri) pada diri mereka. Belas kasih diri adalah menghibur diri dan peduli ketika diri sendiri mengalami penderitaan, kegagalan, dan ketidaksempurnaan serta dapat mengambil makna dari kesulitan tersebut dan mengubahnya ke hal yang lebih positif (Hidayati dalam Karinda, 2020). Hal ini menimbulkan keingintahuan peneliti untuk melihat gambaran self-compassion mahasiswa tingkat akhir prodi bimbingan dan konseling Universitas Negeri Yogyakarta pada masa pandemi covid 19. 


\section{METODE PENELITIAN}

Penelitian ini menggunakan pendekatan kuantitatif, dengan jenis penelitian deskriptif dan menggunakan analisis deskriptif. Hal ini berdasarkan tujuan penelitian yang akan dicapai yaitu mengetahui gambaran tingkat self-compassion (welas diri) mahasiswa tingkat akhir prodi bimbingan dan konseling Universitas Negeri Yogyakarta pada masa pendemi covid19. Populasi dalam penelitian ini adalah seluruh mahasiswa tingkat akhir program studi Bimbingan dan Konseling di Universitas Negeri Yogyakarta tahun ajaran 2020/2021. Teknik pengambilan sampel dengan menggunakan purposive sampling dengan alasan karena sampel yang akan diambil memiliki kriteria tertentu yaitu mahasiswa yang telah menyelesaikan KKN dan praktik kependidikan serta sedang menyusun tugas akhir skripsi. Dengan demikian sampel dalam penelitian ini adalah mahasiswa tingkat akhir prodi bimbingan dan konseling di Universitas Negeri Yogyakarta sebanyak 36 mahasiswa.

Variabel penelitian ini adalah self-compassion mahasiswa tingkar akhir Prodi Bimbingan dan Konseling di Universitas Negeri Yogyakarta pada masa pandemi covid-19. Data penelitian akan dikumpulkan dengan instrumen self-compassion (welas diri) berupa skala welas diri yang mengungkap tingkat welas diri (self-compassion) mahasiswa tingkat akhir. Setiap responden akan memilih alternatif jawaban dari skala 1 yaitu hampir tidak pernah sampai skala 5 yaitu hampir selalu dengan pertanyaan favorable maupun unfavorable. Skala welas diri dalam penelitian ini mengadopsi Skala Welas Diri (SWD) dari Dicky Sugianto yang merupakan versi bahasa Indonesia dari Self-Compassion Scale (SCS) dari Neff tahun 2003 (Sugianto dkk., 2020).

Penelitian ini menggunakan analisis deskriptif yang akan mengungkap gambaran tingkat self-compassion dari 36 mahasiswa tingkat akhir yang sedang menyelesaikan tugas akhir di Prodi Bimbingan dan Konseling Universitas Negeri Yogyakarta pada masa pandemi covid-19. Pemilihan analisis deskriptif didasarkan pada tujuan penelitian dan pengambilan sampel dengan nonprobability sampling yaitu purposive sampling (ada kriteria khusus pada sampel) sehingga tidak dapat dilakukan generalisasi yang merupakan asumsi penggunaan analisis inferensial. Dengan demikian, hasil penelitian yang didapatkan dari analisis deskriptif ini hanya akan diberlakukan untuk 36 mahasiswa tingkat akhir Prodi Bimbingan dan Konseling di Universitas Negeri Yogyakarta.

\section{HASIL DAN PEMBAHASAN}

Hasil penelitian terkait self-compassion yang telah dilakukan pada mahasiswa tingkat akhir Program Studi Bimbingan dan Konseling di Universitas Negeri Yogyakarta secara keseluruhan dapat dilihat pada Tabel 1 dan Tabel 2.

Tabel 1. Deskripsi Self-compassion

\begin{tabular}{cccccc}
\hline Variabel & $\begin{array}{c}\text { Jumlah } \\
(\mathbf{N})\end{array}$ & $\begin{array}{c}\text { Rata-rata } \\
(\text { Mean })\end{array}$ & $\begin{array}{c}\text { Standar } \\
\text { deviasi }\end{array}$ & Minimal & Maksimal \\
\hline Self-compassion & 36 & 86,44 & 11,39 & 60 & 112 \\
\hline
\end{tabular}


Hasil penelitian menunjukkan bahwa self-compassion dari 36 mahasiswa tingkat akhir yang sedang menyelesaikan tugas akhir di Prodi Bimbingan dan Konseling UNY pada masa pandemi covid-19 sebagian besar memiliki self-compassion sedang $(86,1 \%)$ dapat dilihat pada tabel 2 dengan rata-rata 86,44 (dapat dilihat pada tabel 1).

Tabel 2. Kategori Self-compassion

\begin{tabular}{llcccc}
\hline & & Frequency & Percent & Valid Percent & Cumulative Percent \\
\hline \multirow{4}{*}{ Valid } & Tinggi & 4 & 11.1 & 11.1 & 11.1 \\
& Sedang & 31 & 86.1 & 86.1 & 97.2 \\
& Rendah & 1 & 2.8 & 2.8 & 100.0 \\
& Total & 36 & 100.0 & 100.0 & \\
\hline
\end{tabular}

Self-compassion merupakan salah satu bahasan yang dapat menjelaskan bagaimana individu mampu bertahan, memahami dan menyadari makna dari sebuah kesulitan sebagai hal yang positif (Hasanah \& Hidayati, 2017). Self-compassion is an emotionally positive selfattitude that should protect against the negative consequences of self-judgment, isolation, and rumination such as depression (Neff, 2003). Sikap diri yang positif untuk menerima diri sendiri dan melindungi diri sendiri dari adanya tekanan dan hambatan yang dialami dalam kehidupan yang dapat menimbulkan gangguan kesehatan mental dan merusak diri sendiri. Self-compassion adalah penerimaan oleh diri sendiri dengan cara menunjukkan kebaikan pada diri dan memiliki kesadaran penuh atas masalah yang muncul (Rananto \& Hidayati, 2017).

Hal ini tidak berarti bahwa dengan self-compassion yang dimiliki individu menjadikan diri menjadi egois dan tidak peduli dengan orang lain serta memanjakan diri sendiri. It should also counter the tendencies towards narcissism, selfcenteredness, and downward social comparison that have been associated with attempts to maintain selfesteem (Neff, 2003). Dengan menyayangi diri sendiri akan meningkatkan kasih sayang dan peduli terhadap orang lain. Self-compassion entails seeing one's own experience in light of the common human experience, acknowledging that suffering, failure, and inadequacies are part of the human condition, and that all people-oneself included-are worthy of compassion (Neff, 2003). Dengan demikian self-compassion lebih tepat sebagai perasaan pengampunan pada diri sendiri dan penerimaan apa adanya terhadap diri sendiri. Feeling compassion for oneself is similar to feeling forgiveness for oneself (Neff, 2003).

Dengan adanya self-compassion pada diri seseorang maka akan menyebabkan adanya semangat dan motivasi dalam menghadapi segala hambatan yang ada sepanjang kehidupan. Hal ini berguna bagi mahasiswa yang sedang berjuang dalam proses peneyelesaian tugas akhir khususnya di era pandemi covid-19 yang memiliki hambatan serta rintangan yang khusus dihadapi mahasiswa. Mahasiswa membutuhkan ketahanan terhadap rintangan dan semangat dalam penyelesaian tugas akhir. Dengan demikian, mahasiswa yang memiliki selfcompassion yang tinggi akan memiliki resiliensi tinggi dan prokrastinasi yang rendah yang memudahkan dalam proses penyelesaian tugas akhir di era pandemi covid-19.

Hal ini berdasarkan penelitian Hatari \& Setyawan (2020) pada mahasiswa yang sedang mengerjakan skripsi diperoleh bahwa ada hubungan positif antara selfcompassion dengan resiliensi, semakin tinggi self-compassion maka semakin tinggi resiliensi mahasiswa, demikian pula sebaliknya semakin rendah self-compassion maka semakin rendah resiliensi. Penelitian Rananto \& Hidayati (2017) diperoleh hasil yang 
menyatakan bahwa semakin tinggi self-compassion maka semakin rendah prokrastinasi, sebaliknya semakin rendah self-compassion maka semakin tinggi prokrastinasi. Selain itu, individu yang memiliki self-compassion yang tinggi lebih termotivasi untuk berjuang lebih baik dan berkembang lebih baik. Dengan kata lain adanya motivasi instrinsik untuk berjuang dalam menghadapi kesulitan yang dimiliki pada seseorang dengan self-compassion tinggi. Self-compassionate individuals are motivated to learn and grow, but for intrinsic reasons not because they want to garner social approval (Neff, 2009).

Self-compassion memiliki komponen antara lain mengasihi diri, menghakimi diri, kemanusiaan universal, isolasi, kewawasan dan overidentifikasi. Self-compassion is conceptualized as containing 3 core components: self-kindness versus self-judgment, common humanity versus isolation, and mindfulness versus overidentification, when relating to painful experiences (Germer \& Neff, 2013). Komponen self-compassion saling berlawanan yaitu self-kindness (mengasihi diri) versus self-judgment (menghakimi diri), common humanity (kemanusiaan universal) versus isolation (isolasi), mindfulness (kewawasan) versus overidentification (overidentifikasi).

Komponen positif terdiri dari mengasihi diri (self-kindness), kemanusiaan universal (common humanity), dan kewawasan (mindfulness). Komponen negatif terdiri dari selfjudgment (menghakimi diri), isolation (isolasi), overidentification (overidentifikasi). Komponen-komponen tersebut adalah: (1) mengasihi diri (self-kindness) yang merupakan sikap hangat dan penuh pengertian terhadap diri, yang berkebalikan dengan menghakimi diri (self-judgment) yang merupakan sikap penuh penghakiman dan dingin terhadap diri; (2) kemanusiaan universal (common humanity) yang melibatkan kesadaran bahwa setiap manusia menderita dan mengalami kegagalan, yang berkebalikan dengan isolasi (isolation) perasaan bahwa hanya diri sendiri yang menderita; dan (3) kewawasan (mindfulness) yang merupakan kesadaran akan pengalaman penderitaan dalam perspektif yang berimbang, yang berkebalikan dengan overidentifikasi (overidentification) dimana seseorang larut dalam perasaan menderita (Neff et al., dalam Sugianto dkk., 2020).

Tabel 3. Self-compassion Dilihat Dari Tiap Aspek

\begin{tabular}{lccc}
\hline \multicolumn{1}{c}{ Aspek } & Tinggi & Sedang & Rendah \\
\hline Mengasihi Diri & $\mathbf{1 8}(\mathbf{5 0 \%})$ & $\mathbf{1 8}(\mathbf{5 0 \%})$ & $0(0 \%)$ \\
Menghakimi Diri & $5(13,9 \%)$ & $\mathbf{2 4}(\mathbf{6 6 , 7 \%})$ & $7(19,4 \%)$ \\
Kemanusiaan Universal & $\mathbf{2 4}(\mathbf{6 6 , 7 \%})$ & $12(33,3 \%)$ & $0(0 \%)$ \\
Isolasi & $5(13,9 \%)$ & $\mathbf{2 1}(\mathbf{5 8 , 3 \%})$ & $10(27,8 \%)$ \\
Kewawasan & $17(47,2 \%)$ & $\mathbf{1 9}(\mathbf{5 2 , 8 \%})$ & $0(0 \%)$ \\
Overidentifikasi & $3(8,3 \%)$ & $\mathbf{2 7}(\mathbf{7 5 \%})$ & $6(16,7 \%)$ \\
\hline
\end{tabular}

Berdasarkan hasil penelitian yang tercantum pada tabel 3, terdapat komponen positif yang berkategori tinggi yaitu mengasihi diri dan kemanusiaan universal, sedangkan pada komponen kewawasan berada pada kategori sedang yang diharapkan dapat ditingkatkan untuk menjadikan self-compassion yang tinggi. Komponen yang berlawanan atau negatif yaitu menghakimi diri, isolasi, dan overidentifikasi berada pada kategori sedang dan diharapkan dapat dikurangi agar menjadi kategori rendah. Dengan hal tersebut, selfcompassion (welas diri) mahasiswa yang semula berkategori sedang maka diharapkan dapat meningkat menjadi kategori tinggi. Seseorang dikatakan berwelas diri ketika ia memiliki 
tingkat komponen positif yang tinggi yang diikuti dengan tingkat komponen negatif yang berkurang (Neff et al., dalam Sugianto dkk., 2020).

Self-compassion yang tinggi diperlukan mahasiswa tingkat akhir dalam proses penyelesaian tugas akhir. Berkurangnya penghakiman terhadap diri, berkurangnya perasaan bahwa penderitaan hanya terjadi pada diri sendiri, dan larut dalam perasaan menderita ketika menghadapi hambatan dan kesulitan ketika proses penyelesaian tugas akhir merupakan bukti bahwa sudah ada self-compassion pada diri seseorang. Seseorang akan lebih menerima diri apa adanya ketika menghadapi situasi yang sulit dan tidak menyenangkan.

Neff (dalam Ramadhani \& Nurdibyanandaru, 2014) mengemukakan bahwa selfcompassion yang tinggi dapat membuat seseorang merasakan kenyamanan dalam kehidupan sosial dan lebih menerima diri secara apa adanya, dapat menghadapi situasi yang bersifat negatif. Self-compassion pada mahasiswa dapat ditingkatkan dengan menerima seutuhnya diri dan penuh pemahaman terhadap diri sendiri. Sikap yang menerima dan tidak menilai diri sendiri, bebas dari perbandingan dengan orang lain, dan self-compassion tinggi memberi perasaan diterima dan aman pada diri sendiri (Lim \& Kartasasmita, 2019).

\section{SIMPULAN}

Self-compassion dari 36 mahasiswa tingkat akhir yang sedang menyelesaikan tugas akhir di Prodi Bimbingan dan Konseling Universitas Negeri Yogyakarta pada masa pandemi covid-19 sebagian besar memiliki self-compassion kategori sedang. Mahasiswa tingkat akhir membutuhkan ketahanan terhadap rintangan dan semangat dalam penyelesaian tugas akhir khususnya di era pandemi covid-19 yang memiliki hambatan serta rintangan yang khusus dihadapi mahasiswa. Dengan self-compassion yang tinggi pada mahasiswa maka menimbulkan resiliensinya tinggi dan prokrastinasi rendah, serta lebih termotivasi untuk berjuang lebih baik dalam proses penyelesaian tugas akhir khususnya di era pandemi covid19.

Ada komponen self-compassion yang masih perlu ditingkatkan yaitu kewawasan (mindfulness) yang merupakan kesadaran akan pengalaman penderitaan dalam perspektif yang berimbang dan juga ada komponen yang perlu dikurangi agar mahasiswa tingkat akhir memiliki self-compassion yang tinggi khususnya selama proses penyelesaian tugas akhir. Berkurangnya penghakiman terhadap diri, berkurangnya perasaan bahwa penderitaan hanya terjadi pada diri sendiri, dan larut dalam perasaan menderita ketika menghadapi hambatan dan kesulitan ketika proses penyelesaian tugas akhir adalah yang diharapkan terjadi pada mahasiswa tingkat akhir. Diperlukan adanya bantuan intervensi berupa layanan bimbingan dan konseling untuk membantu mahasiswa tingkat akhir dalam meningkatkan selfcompassion khususnya ketika menyelesaikan tugas akhir di masa pandemi covid-19 yang memiliki hambatan dan kesulitan tersendiri. 


\section{DAFTAR PUSTAKA}

Aulia, S., \& Panjaitan, R. U. (2019). Kesejahteraan psikologis dan tingkat stres pada mahasiswa tingkat akhir. Jurnal Keperawatan Jiwa, 7(2), hlm. 127-134.

Bluth, K., \& Neff, K. D. (2018). New frontiers in understanding the benefits of selfcompassion. Self and Identity, 1(1), hlm. 1-4. doi:10.1080/15298868.2018.1508494

Elices, M., Carmona, C., Pascual, J. C., Feliu-Soler, A., Martin-Blanco, A., \& Soler, J.(2017). Compassion and self-compassion: Construct and measurement. Mindfulness \& Compassion, 2(1), hlm. 34-40.

Firman. (2020). Dampak covid-19 terhadap pembelajaran di perguruan tinggi. Bioma, 2(1), hlm.14-20.

Germer, C. K., \& Neff, K. D. (2013). Self-compassion in clinical practice. Journal of clinical psychology, 69(8), hlm. 856-867.

Hasanah, F. A., \& Hidayati, F. (2017). Hubungan antara self-compassion dengan alienasi pada Remaja (Sebuah studi korelasi pada siswa SMK Negeri 1 Majalengka). Jurnal Empati, 5(4), hlm. 750-756.

Hatari, S., \& Setyawan, I. (2020). Hubungan antara self-compassion dengan resiliensi pada mahasiswa yang sedang mengerjakan skripsi di fakultas psikologi universitas diponegoro. Jurnal Empati, 7(1), hlm. 54-59.

Karinda, F. B. (2020). Belas Kasih Diri (Self-compassion) pada Mahasiswa. Cognicia, 8(2), hlm. 234-252.

Krisdianto, M. A., \& Mulyanti, M. (2015). Mekanisme Koping dengan Tingkat Depresi pada Mahasiswa Tingkat Akhir. Jurnal Ners dan Kebidanan Indonesia, 3(2), hlm. 71-76.

Lim, M. T. A. F., \& Kartasasmita, S. (2019). Dukungan Internal atau Eksternal; SelfCompassion dan Perceived Social Support Sebagai Prediktor Stres. Jurnal muara ilmu sosial, humaniora, dan seni, 2(2), hlm. 551-562.

Neff, K. (2003). Self-compassion: An alternative conceptualization of a healthy attitude toward oneself. Self and identity, 2(2), hlm. 85-101.

Neff, K. D. (2009). The role of self-compassion in development: A healthier way to relate to oneself. Human development, 52(4), hlm. 211.

Neff, K. D., \& Vonk, R. (2009). Self-compassion versus global self-esteem: Two different ways of relating to oneself. Journal of personality, 77(1), hlm. 23-50.

Ramadhani, F., \& Nurdibyanandaru, D. (2014). Pengaruh self-compassion terhadap kompetensi emosi remaja akhir. Jurnal Psikologi Klinis dan Kesehatan Mental, 3(03), hlm. 121.

Rananto, H. W., \& Hidayati, F. (2017). Hubungan Antara Self-compassion dengan Prokrastinasi pada Siswa SMA Nasima Semarang. Empati, 6(1), hlm. 232-238. 
Sugianto, D., Suwartono, C., \& Sutanto, S. H. (2020). Reliabilitas dan validitas selfcompassion scale versi Bahasa Indonesia. Jurnal Psikologi Ulayat: Indonesian Journal of Indigenous Psychology, 7(2), hlm. 177-191.

Sugianto, D., Sutanto, H., \& Suwartono, C. (2020). Self-Compassion as a Way to Embrace Loneliness in University Students. PSIKODIMENSIA, 19(1), hlm. 122-131. 
10 | Setiani - Self-Compassion Mahasiswa ... 